\title{
Polytec - new material and technology
}

\author{
Janusz Juraszek ${ }^{1, *}$ \\ ${ }^{1}$ ATH University of Bielsko-Biała, Civil Engineering Dep., Willowa 2, 43-309 Bielsko-Biała Poland
}

\begin{abstract}
The paper describes the possible applications of expanded polystyrene (EPS) granulate derived from recycling for the production of prefabricated building units. Test results of a new material called Polytec and its application in the construction industry are presented. The polytec construction system is based on prefabricated large-panel units. An important advantage of the new material is the volume representation of EPS granulate, which reaches up to $60-70 \%$. So far - in order to keep the proper strength of the manufactured structures lightweight, concretes containing up to $40 \%$ of EPS were used. Increasing the EPS volume in a mixture containing modified cement mortar increases the thermal insulation of the material and, at the same time, reduces the strength of Polytec units. The higher volume representation of recycling EPS granulate enables effective waste management and allows decreasing the use of natural aggregate in the mixture. This, in turn, contributes to more effective environmental protection and lower carbon dioxide emission. An innovative solution for monitoring the strain of selected elements of the Polytec system was proposed based on optical fiber sensors with Bragg grating. They enable conducting both static and dynamic measurements. The monitoring system was installed in a building made of prefabricated elements.
\end{abstract}

\section{Introduction}

The idea of using recycled expanded polystyrene (EPS) appeared with an increasing problem of utilization of styrofoam waste. According to statistics, on a volume basis, EPS forms nearly $7 \%$ of solid waste in landfills in some countries. Since it is a nonbiodegradable material, EPS contributes significantly to the pollution of the environment, and in many European countries these products are being totally banned from landfills, with the originating manufacturer being responsible for their collection, recycling, or disposal [1]. The waste is most often in the form of pieces and granules. The parameters of fragmented EPS used as thermal insulation do not change significantly. Thanks to its shape (small globules), EPS granulate can be used as artificial aggregate in mortars and lightweight concretes. The amount of artificial aggregate significantly affects not only thermal insulating properties but also final strength of produced material. Due to the impact certain ingredients have on the parameters, there is a necessity to find correlations between the amounts of certain components in a mix. Studies involving concrete-related topics approach

* Corresponding author: jjuraszek@ath.bielsko.pl 
different types of building materials with polystyrene granule, such as mortar, concrete, pavement, etc. Waste such as ESP, cork, and tire are often used as additional ingredients in building materials, because they can improve the acoustic and thermal properties [2-5].

\section{Prefabrication system}

The construction system is based on the prefabricated large-panel wall components. The dimensions of the wall panels depend on the shape and size of a building. There is a maximum weight of certain elements, varying from $1,200-1,300 \mathrm{~kg} / \mathrm{pce}$. The final overall dimensions of the panels are determined according the modular grid $70 \times 70 \mathrm{~cm}$ [5] (Fig. 1).

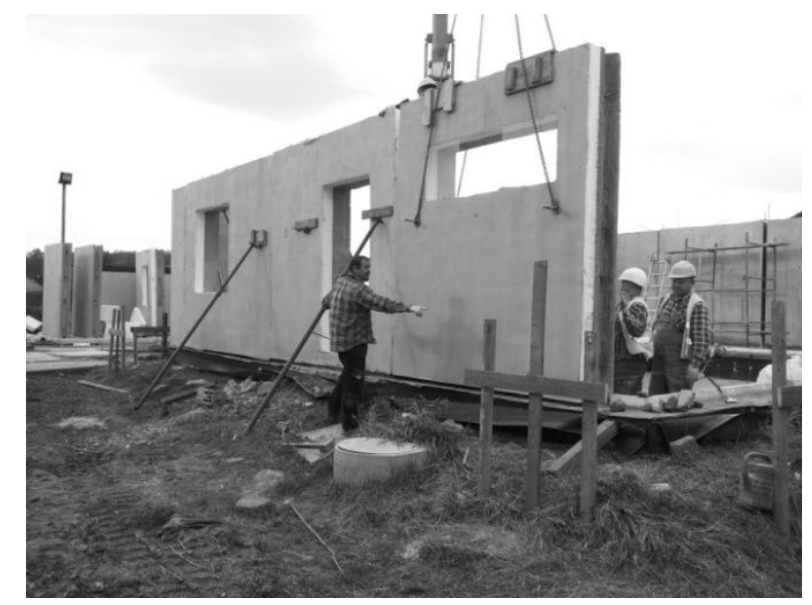

Fig. 1. Installation of panels.

The system enables the construction of buildings of any shape, by using additional, nonstandard reduction panels that allow achieving non-modular dimensions. The designed panels are $2.8 \mathrm{~m}$ high. On top of them, a reinforced concrete rim is mounted, with the ceiling slab in the upper or the lower section of the rim. A proper connection of the ceiling slab with the rim provides more flexibility in shaping the height of the floor by gaining additional 15-20 cm (Fig. 2).

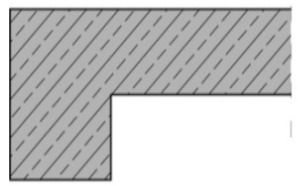

Fig. 2. Schematic cross - section through the rim.

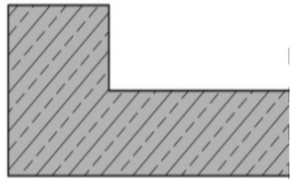

Fig. 3. Cross section though the wall.

The external panels are produced as two-layer walls (Fig. 3). The panel made from the modified Polytec mortar is the load-bearing and, at the same time, insulating element. The load-bearing section is $28-30 \mathrm{~cm}$ thick. Additionally, the main thermal insulation in the wall panels is provided by expanded polystyrene (EPS) with the thickness of $17 \mathrm{~cm}$. The target thickness of the panels manufactured on the production line is $45 \mathrm{~cm}$ (Fig. 4). 


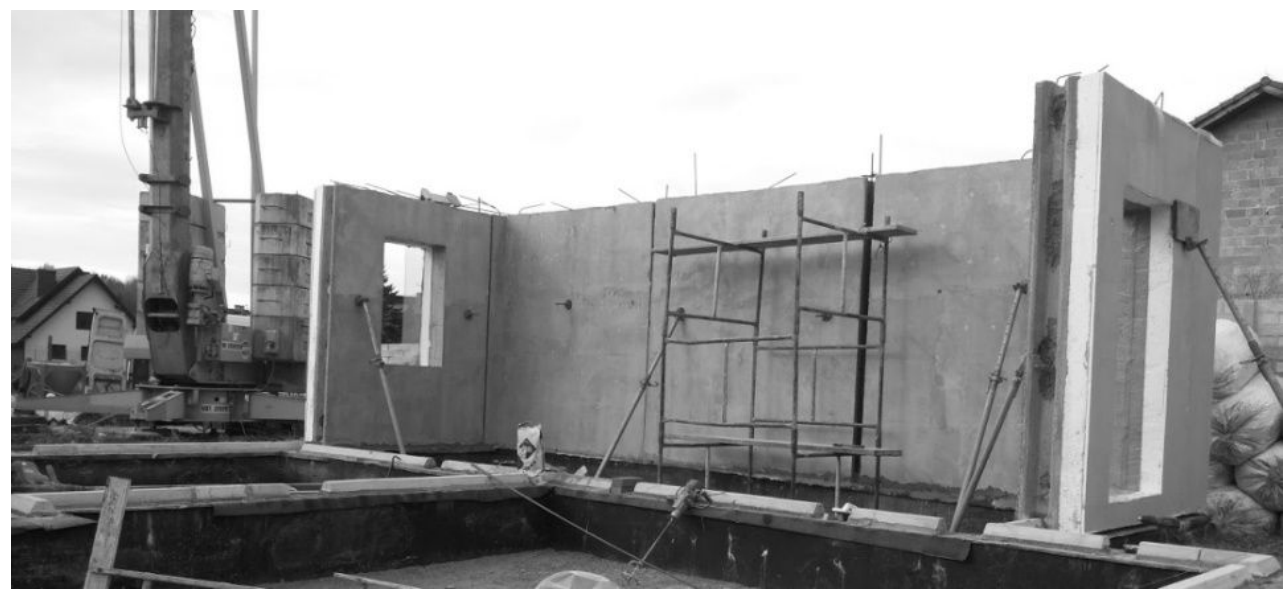

Fig. 4. Polytec panels.

The panels are connected with one another by means of locks profiled during the prefabrication. After being interlocked, the locks create a stay-in-place formwork for the reinforced concrete hexagonal pillars.

During the prefabrication, a grid is inserted into the panels. The grid is connected with the anchors protruding from the locks in the model stay-in-place formwork and creates a permanent connection. The external panels are not finished during the production. An outer layer needs to be made from the grid embedded in the glue-patching mortar, and the external surfaces require finishing. The panels are seasoned in the plant or at the construction site. Ready components are stored until they reach their target strength. The panels are installed by means of quick assembling tower cranes or other lifting machines (Fig. 5, 6).

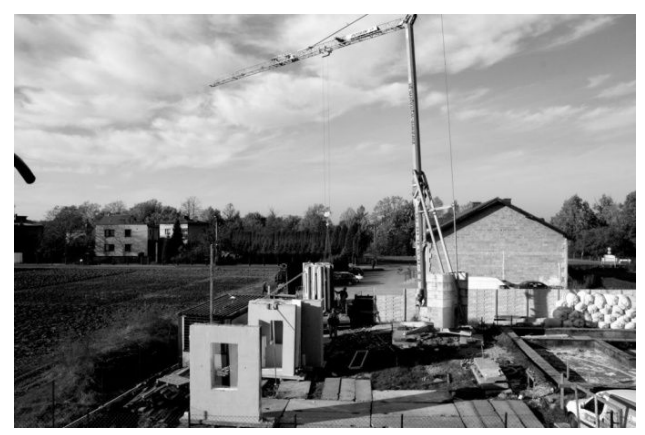

Fig. 5. Installation with the tower crane.

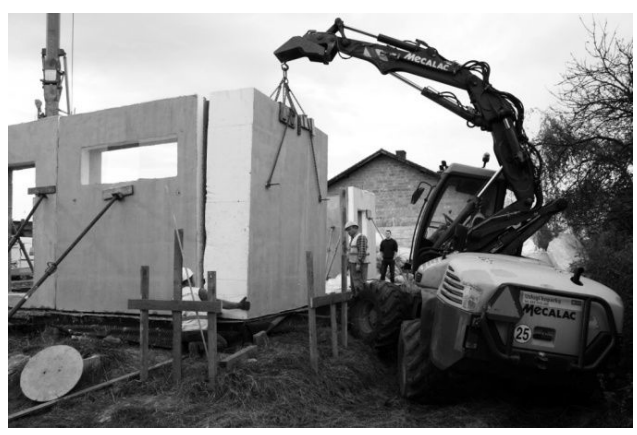

Fig. 6. Installation with the multipurpose machine.

The construction begins with the first floor, erected on the formed and profiled lock, on the traditional foundation that allows placing the panels in one line. The connecting pillars between the panels are mounted on the foundation wall, thus, enabling the loads to be carried from the rim to the foundation (Fig. 7). 


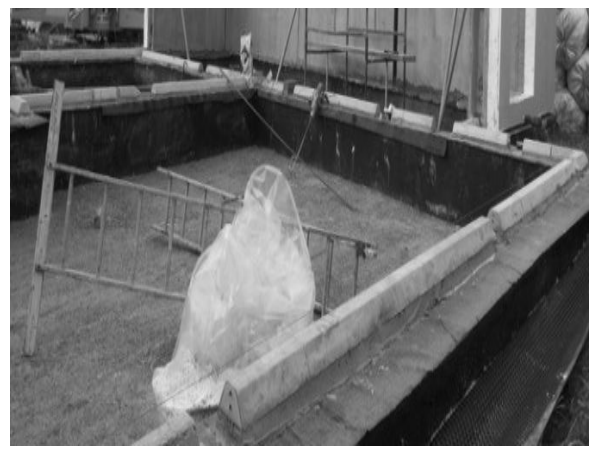

Fig. 7. Profiled installation locks on the foundation wall system.

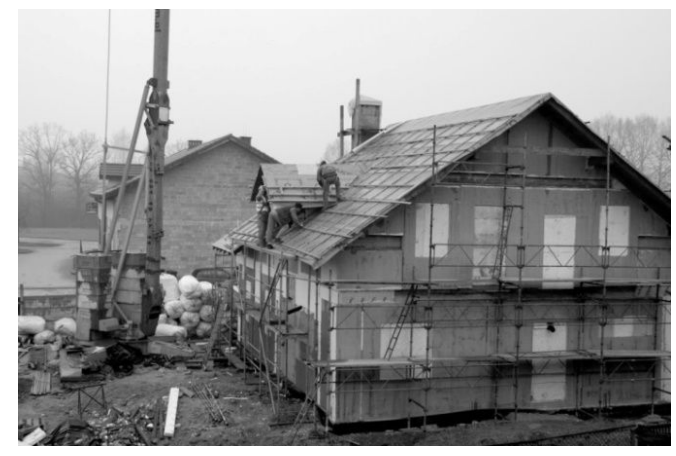

Fig. 8. Building constructed in the Polytec.

The roof structure is mounted on the traditional reinforced concrete rim supported on the reinforced pillars and the Polytec panels (Fig. 8).

\section{Experimental research of POLYTEC material}

Compression testing of normative samples made of POLYTEC material with $60-70 \%$ of polystyrene granules of recycled EPS was conducted. Diameter of EPS granules was between 3-6 mm. The tests were carried out using a ZWICK universal testing machine. The machine accuracy class was 0.5 which means that the highest measurement error of the compressive force did not exceed $0.5 \%$. The material reached full strength after 28 days. The samples were collected in larger elements by water cutting. The results of compression tests are presented in Fig. 9.

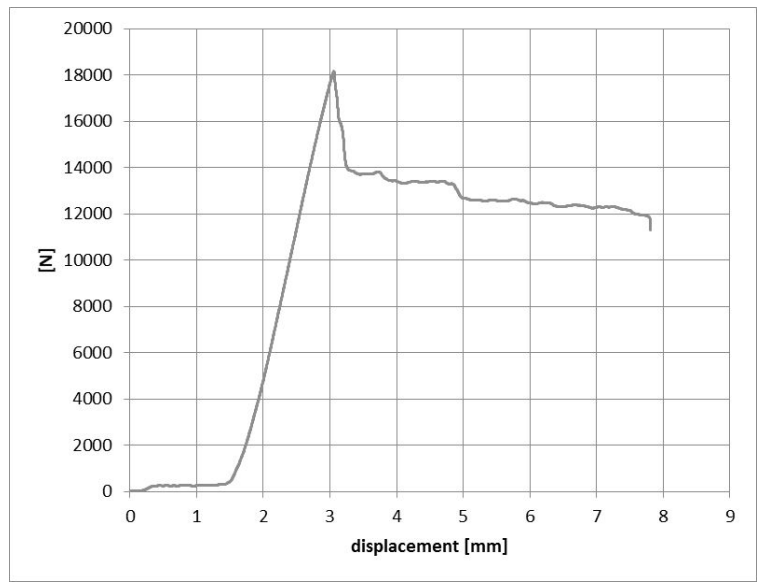

Fig. 9. Force-displacement relation for compresive test.

The highest obtained compressive stress value was $2,87 \mathrm{MPa}$ and the lowest one 1,44 MPa. The average value for 20 measurements was 2,08 $\mathrm{MPa}$ and the square deviation was $0,38 \mathrm{MPa}$. 


\section{Test of the wall and ceiling}

The FBG sensor [6-7] was placed vertically in the wall of the model house described in the previous chapter. The measuring base of the sensor was $500 \mathrm{~mm}$. It was pre-tensioned to $1000 \mu$ strain. Static tests were carried out, loading the ceiling over the sensor with a load $10 \mathrm{kN}$ distributed over a length of $1500 \mathrm{~mm}$. In addition to the static load, the tested area was subjected to a low speed impact load of $\pm 1000 \mathrm{~N}$. A summary list of the determined strain values is shown in Fig. 10.

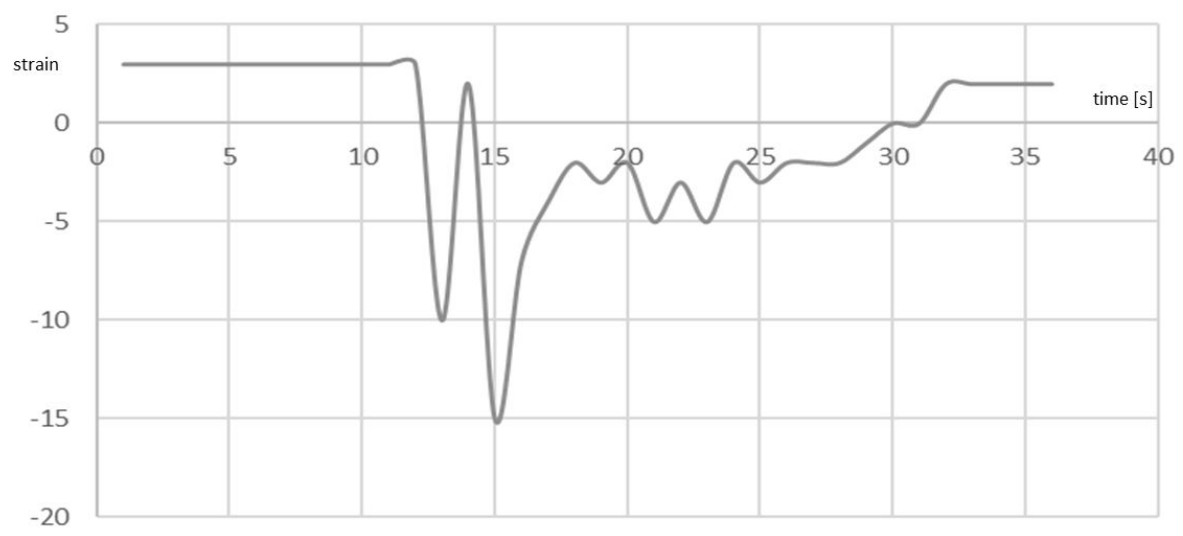

Fig. 10. Strain of the model building wall.

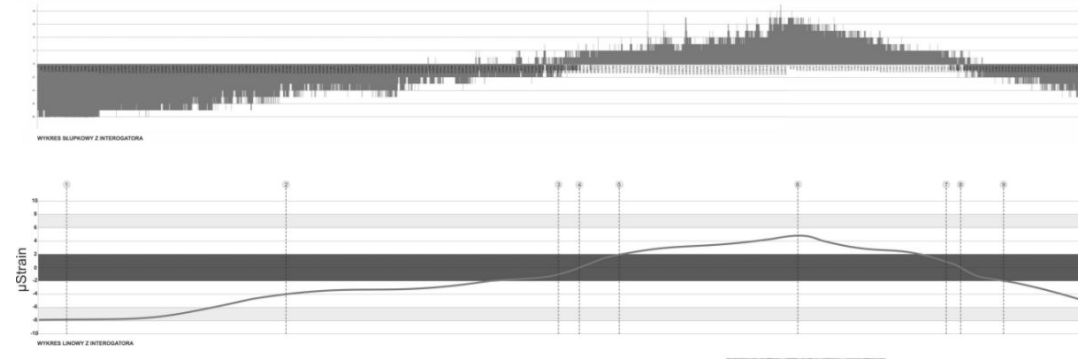

Fig. 11. Strain of the ceiling of the Polytec building.

It can be observed that a relatively large static load does not cause as much distortion as a low speed impact load. Static strain is from 4 to $-3 \mu$ strain, which is a total of approx. $7 \mu$ strain, while dynamic strains reach $-15 \mu$ strain.

Similar tests of the ceiling of the model building were also carried out. The synthetic results of compression tests are presented in Fig. 11. The measured strain is slight despite the considerable ceiling load over the sensor. The total strain was $12 \mu$ strain. After removing the load, the strain returned to the starting point. In Fig. 11 it can also be seen that the surface of the floor had a pre-curvature so that the initial deformation of the ceiling was and was located above the neutral surface (the ceiling bent upwards). The gradual loading of the ceiling caused negative strain, i.e. strain below the neutral surface. 


\section{Conclusion}

The use of concrete with recycling polystyrene granules as a lightweight material for non-structural elements reduces environmental pollution with waste materials and is a reliable solution to reduce construction costs.

Conversion of non-biodegradable waste materials into high quality construction products would be extremely useful in the context of depletion of natural resources.

The FBG monitoring system of a single-family building made of the new material provided a number of relevant pieces of information on the actual deformation and stress distribution of the structure.

\section{References}

1. M. Kekanovic, D. Kukaras, A. Ceh, G. Karaman, Tehnicki vjesnik, 21 (2014)

2. J. Sierra-Perez, I. Lopez-Fornies, J. Boschmonart-Rives, X. Gabarrell, Arch. Min. Sci., 137 (2016)

3. J. Kumar Prusty, S. Kumar Patro, S.S. Basarkar, International Journal of Sustainable Built Environment, 5 (2016)

4. B. Skariah Thomas, R. Chandra Gupta, J. Cleaner Prod, 113 (2016)

5. O.A. Abaza, Z.S. Hussein, J. Mater. Civ. Eng., 28 (2015).

6. J. Juraszek, Arch. Min. Sci., 2, 321-334 (2018)

7. J.Juraszek, Arch. Min. Sci., 3 (2018) 